\title{
Situation and Future Development Prospect of China's Carbon Market
}

\author{
Jie Shang $^{1}$ \\ ${ }^{1}$ School of Economics, Northwest University for Nationalities, Lanzhou, China \\ Correspondence: Jie Shang, Lecturer, School of Economics, Northwest University for Nationalities, Lanzhou, China. \\ E-mail: shangjie@163.com \\ Received: March 21, 2015 \\ Accepted: April 12, 2015 \\ Online Published: May 4, 2015 \\ doi:10.5430/jms.v6n2p47 \\ URL: http://dx.doi.org/10.5430/jms.v6n2p47
}

This research was supported by the Fundamental Research Funds for the Central Universities of Northwest University for nationalities (Grant No. 31920130097)).

\begin{abstract}
Air pollution has become the bottleneck of China's economic and social development. In according to the property rights trading theory and other country's practice, establishing carbon market seems to be the only means with higher economic efficiency to reduce carbon emissions. At present, China's Carbon market is still in the initial stage. This paper analyzed the current situation and problems in China's carbon market. The conclusion is that in the further China should set up carbon credits distribution system and trading platform, foster professional certification bodies, establish carbon license granting mechanisms and train talents on carbon trading to promote China's carbon market development. There are few domestic research on this topic, hopefully this paper helped reader understand the situation of China's carbon market and attract more research on it.
\end{abstract}

Keywords: carbon emissions, externality, the system construction

\section{Introduction}

Since China's reform and opening up, Chinese seems to overly focused on economic development, the importance of environment protection is not be aware. In recent years the repetitive "hazy weather" shows the seriousness of China's air pollution.

At present, China's carbon emissions ranks first in the world, climate change has been incorporated into China's national development strategy.

In 2011 the state council issued "The Comprehensive Energy Saving and Emission Reduction Work in the Twelfth Five-Year" and "The Scheme for Control Greenhouse Gas Emissions in the Twelfth Five-Year". It was made cleard that the carbon dioxide emissions will decreased by $17 \%$ at the end of 2015 compared with 2010 .

Various measures would be taken to reduce carbon emission, such as implement emission-reduction technology in the high-carbon factories, develop and produce new energy, restructure the industrial structure. But in the long term, measures from the system level are integral.

\section{Current Situation of the Development of Chinese Carbon Market}

\subsection{China Has an Advantage on CDM Development, but Still Lack of Pricing Power}

China belongs to the Kyoto protocol in annex ii, in which countries do not need to undertake international reduce obligations. But it is obvious that the international community tried to bring China into the mandatory carbon reduction list as soon as possible. As a country emitting significant amounts of carbon dioxide, there is increasing pressure on China to reduce emission. In 2009, at the Copenhagen world climate conference, China promised that by 2020 reduce the per GDP carbon dioxide emissions $40 \%-45 \%$ than 2005.In recent years, the proportion of CDM program which exploit by China increases constantly. 


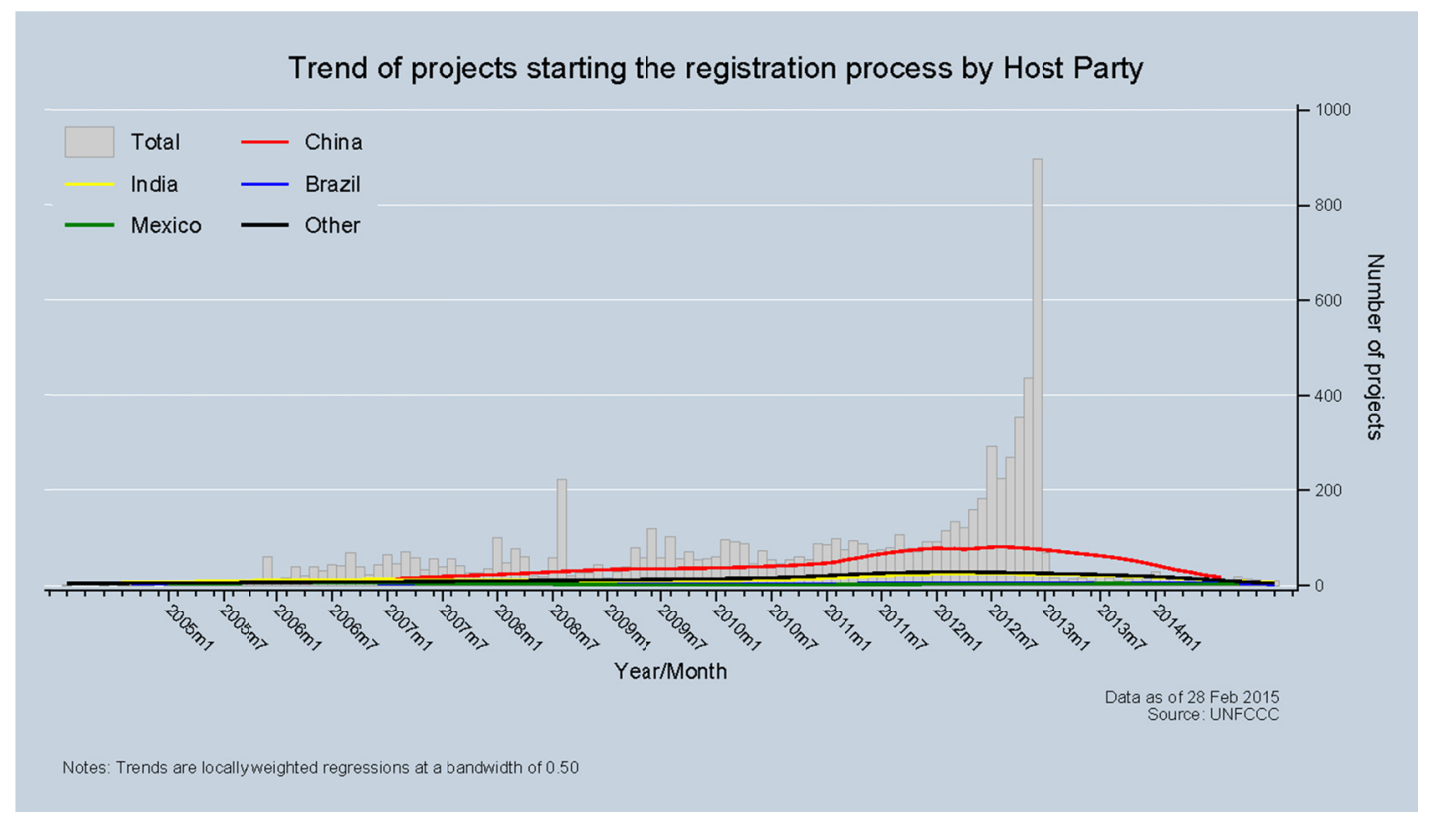

Figure 1. Trend of projects starting the registration process by Host Party (Note 1)

But due to the carbon trading market and the standard are all abroad, domestic enterprises are inexperienced in negotiations, in addition to relevant intermediary service is lacking, a large number of carbon credits which were created by China's enterprises have to be sold in very low price to the international buyers, who restructure or register the credits and sell them in much higher price then. China is actually still in the end of the international carbon emissions industry chain, bargaining power is weak, profit margins are low.

\subsection{Domestic Carbon Market Has Not Yet Taken Shape}

In early 2012, the national development and reform commission agreed to set up carbon emissions trading pilot in Beijing, Tianjin, Shanghai, Chongqing, Hubei, Guangdong and Shenzhen. The establishment of the environment exchange marked China has taken a substantial step forward on environmental enhancement through market. As to government, environment exchange will become a powerful tool and important platform to promote energy conservation and emissions reduction.

But now in the environment exchange, most trades are still voluntary emissions trading. The number of traders is small, carbon reading is inactivity, and the demonstration effect is limited. While the mandatory emissions trading, highest form of carbon emissions trading has not been carried out. There are many problems in the only a handful of voluntary "carbon neutral" trading, such as sell repeatedly and the buyer obtain the "carbon neutral" label with only a small symbolic amount of carbon trading. Therefore the establishment of the environment exchange does not mean that China has established the carbon trading market. It is even far away from the establishment of carbon market mechanism. Lacking perfect carbon market result in domestic enterprises operates outside the main internal carbon market all the time, they can't really adapt to the rules of carbon trading. China has no voice in the rule making, go without saying having the pricing power.

\section{Necessity and Obstacle in Developing and Improving China's Carbon Emissions Trading Market}

\subsection{The Necessity of Improving China's Carbon Market}

3.1.1 Constructing the Carbon Market Is the Requirement of Following the Tendency of International Climate Negotiations

The European Union, the United States and Australia and other major countries and regions have established their own carbon market. The EU has brought the global airline industry into the EU emissions trading system, and EU is inclined to bring the carbon standards into international trade. It cannot be ruled out that there will be more trade barriers based on carbon emissions standards in future. China may face more carbon emission pressure come from the international community. Set up their own carbon emissions trading system and to familiar with and participant the international carbon trading rules is an important measure to safeguard China's interests. 


\subsubsection{Carbon Market Can Promote the Introduction and Development of Carbon Reduction Technology}

On the one hand, at present most of the carbon trade that Chinese enterprises participant are based on CDM, therefore the buyers are international buyers. In carbon reduction projects, the foreign corporation may provide technical support and guidance. Chinese companies could acquire the advanced technology of emissions reduction through these projects.

On the other hand, national carbon markets will be build, which means each corporate would be restraintd by emissions constraints, in this case, the enterprise which can control its emission within the limit could sell its redundant carbon quotas to others who need.

This kind of incentive mechanism also may encourage enterprises to adopt carbon reduction technology.

\subsubsection{Carbon Market Could Finance China's Carbon Emissions Reduction}

China's carbon emissions are rank the world's first, for the energy conservation and environment protection reason, China has to make deep reductions. But carbon reduction needs large sums of money. According to the statistics of McKinsey global institute and the global energy and material consulting business department, China may needs \$28 billion each year if she reduces energy demand $1 \%$ by changing energy productivity mode (Note 2 ). The huge financial gap is the main bottleneck restrict China's carbon reductions, establishing carbon market can partly solve this problem.

\subsection{The Difficulties in the Process of Carbon Market Develop}

\subsubsection{Allocation of Domestic Carbon Credits}

"The essence of property rights is the right of exclusive." (Note 3) "Property does not refer to the relationship between persons and properties, but rather the relationship between people caused by the presence of propertity. Ownership arrangements determined everyone's acts according to the appropriate norms, everyone must comply with the relationship between other people, or bear the cost of non-compliance with this relationship, so it is used to determine the social relationship and status when the person using the scarce resources." (Note 4)

Thus, first of all, property rights is the exclusive private property, the human social behavior norms forms on this basis.

But the public nature resource property is a special property, which belongs to the public, for its strong inseparability, any individual can not separate his property right and trade it independently. If establishing a national mandatory carbon trading system, the local government will naturally to be the public property agent. Distributed the carbon emissions quotas among regions fairly is the basis of carbon market. A carbon emission right is closely related to the local development, well-developed provinces and underdeveloped provinces have their respective reasons for more carbon quotas. It is so difficult to make an allocate plan that be agreed.

\subsubsection{Local Trading Platform Separated with Each Other, and Function of Price Discovery Is Weak}

The purpose of establishing carbon market is to allocate carbon emissions rights by market-oriented ways in a nationwide. Only the national market could cofigurate carbon emission resources through out the whole nation. While regional markets do not has such fountain.

At present, besides the three large Environment Exchange in Beijing, Shanghai and Tianjin, various small local exchanges are established in Wuhan, Hangzhou, Changsha, and Kunming and so on. Trade in those exchanges is inactive, just barely run. More regions are still eager to establish a carbon exchange, building redundant exchange is a waste and in separated local exchange, the trade volume is too small to discovering effective carbon prices by competition Establishing a national carbon trading platform as soon as possible is necessary for China's carbon emissions trading development.

\subsubsection{Lacking Third-Party Certification System}

True and accurate emissions data is the primary guarantee for carbon emission reduction system. In usually, data provided by emission entity, but for the benefit of itself, there is a tendency to provide false data, thus a certification system to guarantee the accuracy of data is necessary. A complete certification system should include qualification, principles, norms and legal responsibilities in certification.

According to the international practice, the third-party certification body is an assisted trading institutions which usually accredited by the United Nations Executive Board and independent of both sides of the trade. Carbon emissions certification body is indispensable in the transaction, but until now in all of the private certification bodies that be designated by United Nations Executive Board, only two are China's institutions, which brought great 
inconvenience to the corporate who supply carbon emission reduction units. Meanwhile, certification principles, norms, certification processes and relevant legislation in the country is nearly blank, for a country which supply half of the world's CDM, the absence of such a system is a serious constraint to further development of carbon market.

\subsubsection{System and Policies Don’t Meet the Needs of Carbon Market Development}

Adequate and effective policy is the foundation of transferring social resources, funds and corporates to the low carbon field, it is also a strong guarantee for the coordination of economic interests and social interests. Currently, the carbon policy lags behind the development of the carbon market trends, the main reasons can be summarized as follows:

First, the carbon emissions permit system has not yet been established. Carbon emissions permit system is based on the fixed number of emission credits, which will be allocated to emitters through free or auctioned permits. On this basis, emitters exchange emission permits with each other, and therefore carbon emissions permit system is the necessary condition of mandatory carbon trading, but China has not really set carbon emission permits system.

Second, the government did not clearly recognize what is low carbon economy. Although the country introduced a series of low-carbon policies in recent years, but these policies are mostly macro-dominant, with few rules can be implemented. Especially the local government never has a clear understanding of what kind of policy can promote local economic develop in a low-carbon model and enabling enterprises to obtain benefits by carbon emission reduction.

Third, monetary and fiscal policies did not give strong support and encouragement.

Many technology services company who has registered CDM projects, but its scale is so small and the operating income is so little that it does not meet the requirements to obtain loans from banks, while the government has not given appropriate incentives to financial institutions to help these corporate, thus the corporate may lose develop opportunities. And in current, the tax breaks are given to corporate who meets the emission reduction rate, but the deduction rate is too simple that never consider of the differences in industries, so they are not reasonable regulations to stimulate the supply of carbon emission reduction units.

\subsubsection{Talent Training Can Not Meet Further Demand}

Carbon exchange needs professional who has both composite expertise and experience in carbon trading. They should master the technology such as equipment and energy consumption characteristics, energy audits and project budget but also have abilities on financing arrangements such as carbon rights pledge financing, carbon funds, carbon factoring, carbon bonds, and also familiar with the national energy policy and international trade rules. In carbon trading, the emissions agreement and negotiation process is quite complex, experience in terms of negotiation, payment terms, costs and earnings estimates are all necessary.

\section{Solutions}

\subsection{Set up Quota Allocation Scheme Combining Government and Market}

Carbon emissions trading should include two transaction levels: The first level is the primary market, on this market state trade with emitters; the second level is the secondary market, on which carbon emissions trade with each other.

Because carbon emission rights are public good, thus establishing a fair emission rights distribution mechanism in primary market is critical. At present, most countries and regions distribute emission rights by a mechanism combining free allocation and auctions, free allocation is the main form, such as the U.S. acid rain program, the UK's carbon emissions trading scheme and the EU Emissions Trading Scheme (ETS). China can refer to the ETS, allocate free at the beginning, and then increase the proportion of auctions gradually.

On the initial emission rights allocation, China should fully take into account regional differences and local emissions in the past. In Kyoto Protocol, developed and developing countries have been treated differently. Developed country take "compelled reduction responsibilities" while developing country take "common but differentiated responsibilities."

China could learn from this model to establish a mechanism and link the eastern and western regions market together. Carry out carbon emissions trading between these two regions, the eastern region provide capital and technology to help the western region reduce emission, they may achieve a win-win trade.

\subsection{Establish a National Carbon Trading Platform as Soon as Possible}

A national carbon trading platform is necessary for carbon trading promoting. On the one hand, the dispersion of regional trade is inimical to the discovery of carbon price. On the national platform the volume of trade will be much 
larger than local exchange. This is necessary to pricing. On the other hand it can also integrate green resources and information to offer convenience to traders.

While the relevant policies and regulations are necessary, different regions should have different emission reduction targets. On this basis, mandatory emission reduction market operation would be promoted. Also, voluntary carbon emission reduction market should be encouraged. And CDM projects under the framework of the "Kyoto Protocol" could be including in.

\subsection{Foster Professional Certification Bodies, Giving Financial Institutions Strong Support}

In the international carbon trading market, third-party certification body is an important subject. Its duty is to check and ratify the enterprises' actual emissions reduction. It is important to the carbon trading market regulation. International practice is United Nations or regional and national government authorities to certification bodies and supervise it strictly .from this, government can oversight of corporate carbon transactions indirectly. China should accelerate the cultivation of third-party certification bodies to provide support services for the implementation of carbon trading and the direct supervision of government regulators.

According to The United Nations and the relevant regulations, certification institution generally should be independent third party which has the legal qualification. Internationally, emissions trading mechanism for certifying basically follow in those four principles: consistency, accuracy, comprehensiveness and verifiability. China can refer to CER certification system and CCX (Chicago Climate Exchange) certification system.

\subsection{Establish Carbon License Granting Mechanisms}

Emissions permit system means that all of the corporate and individuals who discharge pollutants must apply to the environmental protection department for discharge permit, only be permitted body can discharge. The system includes two aspects: First, in the context of local environmental capacity, the environmental authorities can control the total amount of greenhouse gases. Environmental authorities set emission index according to the applicant's scale and technical feasibility. For the corporate who does not exceed the emission index, free emission permits would be distributed. Second, the transfer and sale of emission permit. That is, a series of regulations on emission rights trading between corporate who has surplus permit unite and those who can not reach emission standards.

Emissions permit system is essentially an administrative license. Therefore laws and regulations are necessary to ensure its effectiveness. Currently, the permit system in United States and Europe is complete, China could learn from those countries.

\subsection{The Government Should Guide and Support through the Financial and Fiscal Policy}

The development of carbon market needs a lot of investment, in the early stage, the government's guide and incentives are necessary.

First, the government can establish a carbon emissions reduction fund by direct invest or provide guarantee for it. And encourage financial institutions to establish carbon emissions reduction investment funds or venture capital funds to provide financial support for the environmentally friendly corporate.

Secondly, encourage the various financial institutions such as banks, security companies and insurance companies to provided carbon reduction finance. Develop carbon finance such as energy-saving loans, saving income right mortgage loan, carbon financial planning, CDM consulting services and other innovative financial services.

Third, the government should give tax cuts to those corporate who reduced discharge and banks who provide carbon finance services. Then, corporate may realize the value of reducing carbon discharge.

\subsection{Training Talents on Carbon Trading}

First, colleges and universities should invest more money on environmental economics, energy economics, environmental finance, environmental law and other relevant majors. Second, carbon trading professionals should be listed as shortage talents and delivery talent to Europe and the United States or other countries which has mature carbon market to learn trading rules and experience. Third, the Human Resources and Social Security Ministry and Education Ministry should carry out the "carbon trading eligible employees" training and examinations jointly. Attracting high-quality talent to gather in this area.

\section{References}

Ancev, T., \& Harris, M. (2004). Pigou and Coase Re-visited: Ethics, Norms, and Markets Implications for Environmental and Resource Economics. Paper Selected for the 33th Australian Confer-ence of Economists. 
Baumol, W., \& Oates, W. (1988). The Theory of Environmental Policy ( $2^{\text {nd }}$ ed.). Cambridge, England: Cambridge University Press. http://dx.doi.org/10.1017/CBO9781139173513

Calabresi, G. (1970). Costs of Accidents. New Haven: Yale University Press.

Coase, R. (1960). The Problem of Social Cost. Journal of Law and Economics, 3(1), 1-44. http://dx.doi.org/10.1086/466560

Cropper, M., \& Oates, W. (1992). Environmental Economics: A Survey. Journal of Economic Literature, 30(2), $675-740$.

Demsetz, H. (1972). When Does the Rule of Liability Matter?. Journal of Legal Studies, 1(1), 13-28. http://dx.doi.org/10.1086/467477

Demsetz, H. (1996). The Core Disagreement between Pigou, the Profession, and Coase in the Analyses of the Externality Question. European Journal of Political Economy, 12(4), 565-579. http://dx.doi.org/10.1016/S0176-2680(96)00025-0

Diamond, P., \& Mirrlees, J. (1975). On the Assignment of Liability: The Uniform Case. Bell Journal of Economics, 6(2), 487-516. http://dx.doi.org/10.2307/3003241

Dixit, A., \& Olson, M. (2000). Does Voluntary Participation Undermine the Coase Theorem? Journal of Public Economics, 76(3), 309-335. http://dx.doi.org/10.1016/S0047-2727(99)00089-4

Gauthier, D. (1985). Bargaining and Justice. Ethics \& Economics, Blackwell. http://dx.doi.org/10.1017/S0265052500003204

Joskow, P., \& Schmalensee, R. (1998). The Political Economy of Market-Based Environmental Policy: The U.S. Acid Rain Program. Journalof Law and Economics, 41(1), 37-85. http://dx.doi.org/10.1086/467384

Ostorm, E.E. (1990). Governing the Commons. Cambridge University Press. http://dx.doi.org/10.1017/CBO9780511807763

\section{Notes}

Note 1. http://cdm.unfccc.int/Statistics/Public/CDMinsights/index.html

Note 2. WangYao. The carbon financial global view and layout in China, China economic publishing house, 2010, p. 132.

Note 3. North: " change of the structure in economic history", The Commercial Press, 1992, page 21

Note 4. Liu Shouying: "Property rights and institutional change", Shanghai Joint Publishing, Shanghai People's Publishing House, 1994, p.204. 